\title{
A Sensor-less Ultra-high-Speed Motor Driver
}

\author{
Chung-Wen Hung*, Yan-Ting Yu, Bo-Kai Huang and Wei-Lung Mao \\ Department of Electrical, National Yunlin University of Science and Technology \\ 123 University Road, Section 3, Douliou, Yunlin 64002, Taiwan, R.O.C. \\ *wenhung@yuntech.edu.tw \\ www.yuntech.edu.tw
}

\begin{abstract}
Ultra-high-speed motors play a very important role in machine tools. A speed-sensor-less ultra-high-speed motor driver is proposed in this paper. Without any speed sensor that is extremely expensive, the proposed driver employing a sensor-less estimation scheme can perform a closed-loop control very accurately and efficiently. The design and implementation of the driver and feedback circuits are detailed in this paper. Experimental results show that the proposed system functions very well.
\end{abstract}

Keywords: Ultra-high-Speed Motor, Speed-sensor-less Control, Motor Driver, VVVF Control

\section{Introduction}

The ultra-high-speed motor is an important part of machine tools, and most of these motors are induction motors (IMs) because induction motors are highly reliable and relatively cheap. In the past, there have been many studies discussing various driver methods, including variable-voltage variable-frequency (VVVF) control, vector control, proportional-integrated (PI) control, fuzzy control, and neural-network control.

However, these studies dealt with only normal speed motors, and relatively fewer studies in the literature have discussed driver methods for ultra-high-speed motors [1]-[6]. In [1], the driver efficiency was optimized using the total harmonic distortion (THD) of the motor current with auto-adjust driver voltage. In [2], an ultra-high-speed soft switch inverter was developed to improve the driver efficiency. Both [1] and [2] have proposed new driver methods.

Although conventional IM driver methods, such as open-loop scalar control and VVVF control, are popular because they are relatively easy to implement, some studies have started using closed-loop control. Ref. [3] employed fuzzy rules to determine the VVVF command and to increase the driver efficiency. Ref. [4] proposed a slip frequency compensation method to decrease the speed error. Ref. [5] discussed two vector control methods: field orientation control (FOC) and direct torque control (DTC). The torque responses of both controls are better than those of scalar control methods. For speed estimation, ref. [6] presented two methods: the model reference adaptive system (MRAS) and the least square method (LSM). The former may be used for a wider speed range but is too sensitive to motor parameters, whereas the latter that calculates the speed by iteration is suitable only for a narrow speed range. In this paper, an easier speed estimation method is proposed. The motor slip speed is calculated using the motor model, and then the motor speed is estimated by subtracting the slip speed from the induction magnetic field speed. Without any expensive ultra-high-speed sensor, the proposed driver performed a closed-loop control very accurately and efficiently.

\section{Slip speed estimation}

The slip speed can be calculated from the so-called flux orientation control (FOC) method. The motor model can be simplified by referring to the rotor flux. The derivation is described as (1) - (5). The equation for calculating the slip speed, (4), can be derived by setting 
zero the flux along the q-axis in (3). In (4), there is a variable flux along the d-axis. It can be calculated by (5) using the current on d-axis.

$$
\begin{aligned}
& \phi_{r}^{r}=L_{m} i_{s}^{r}+L_{r} i_{r}^{r} \\
& \rightarrow i_{r}^{r}=\frac{1}{L_{r}}\left(\phi_{r}^{r}-L_{m} i_{s}^{r}\right) \\
& V_{r}^{r}=0=R_{r} i_{r}^{r}+\frac{d}{d t} \phi_{r}^{r}+j \omega_{s l} \phi_{r}^{r} \\
& \rightarrow \frac{d}{d t} \phi_{r}^{r}=\frac{L_{m}}{L_{r}} R_{r} i_{s}^{r}-\left(\frac{R_{r}}{L_{r}}+j \omega_{s l}\right) \phi_{r}^{r} \\
& \frac{d}{d t} \phi_{d r}^{r}=\frac{L m}{L_{r}} R_{r} i_{d s}^{r}-\frac{R_{r}}{L_{r}} \phi_{d r}^{r}+\omega_{s l} \phi_{q r}^{r} \\
& \frac{d}{d t} \phi_{q r}^{r}=\frac{L_{m}}{L_{r}} R_{r} i_{q s}^{r}-\frac{R_{r}}{L_{r}} \phi_{q r}^{r}-\omega_{s l} \phi_{d r}^{r} \\
& \frac{d}{d t} \phi_{q r}^{r}=\frac{L_{m}}{L_{r}} R_{r} i_{q s}^{r}-\frac{R_{r}}{L_{r}} \phi_{q r}^{r}-\omega_{s l} \phi_{d r}^{r} \\
& \rightarrow 0=\frac{L_{m}}{L_{r}} R_{r} i_{q s}^{r}-\omega_{s l} \phi_{d r}^{r} \\
& \rightarrow \omega_{s l}=\frac{L_{m} R_{r}}{L_{r}} \frac{i_{q s}^{r}}{\phi_{d r}^{r}} \\
& \frac{d}{d t} \phi_{d r}^{r}=\frac{L_{m}}{L_{r}} R_{r} i_{d s}^{r}-\frac{R_{r}}{L_{r}} \phi_{d r}^{r}+\omega_{s l} \phi_{q r}^{r} \\
& \rightarrow \frac{d}{d t} \phi_{d r}^{r}=\frac{L_{m}}{L_{r}} R_{r} i_{d s}^{r}-\frac{R_{r}}{L_{r}} \phi_{d r}^{r} \\
& \rightarrow \frac{\phi_{d r}^{r}}{i_{d s}^{r}}=\frac{L_{m}}{\frac{L_{r}}{R_{r}} s+1}
\end{aligned}
$$

where

\begin{tabular}{clcl}
\hline$\phi_{r}^{r}:$ & $\begin{array}{l}\text { rotor flux referred } \\
\text { rotor field }\end{array}$ & $R_{r}:$ & rotor resistor \\
\hline$\phi_{q r}^{r}:$ & $\begin{array}{l}\text { rotor flux of the q- } \\
\text { axis referred rotor } \\
\text { field }\end{array}$ & $\phi_{d r}^{r}:$ & $\begin{array}{l}\text { rotor flux of the d- } \\
\text { axis referred rotor } \\
\text { field }\end{array}$ \\
\hline$L_{m}:$ & mutual inductance & $L_{r}:$ & rotor inductances \\
\hline$\omega_{s l}:$ & slip speed & $V_{r}^{r}:$ & $\begin{array}{l}\text { rotor voltage } \\
\text { referred rotor field }\end{array}$ \\
\hline$i_{s}^{r}:$ & $\begin{array}{l}\text { stator current } \\
\text { referred rotor field }\end{array}$ & $i_{r}^{r}:$ & $\begin{array}{l}\text { rotor current } \\
\text { referred rotor field }\end{array}$ \\
\hline$i_{d s}^{r}:$ & $\begin{array}{l}\text { stator current } \\
\text { referred d-axis } \\
\text { refer rotor field }\end{array}$ & $i_{q s}^{r}:$ & $\begin{array}{l}\text { stator current } \\
\text { referred q-axis } \\
\text { refer rotor field }\end{array}$ \\
\hline
\end{tabular}

The block diagram of the slip speed estimator is shown in Fig 1. The $\theta_{\phi r}$ is the angle of the $\vec{\phi}_{r}$ in (6). In Fig 1, (4) and (5) are performed to estimate the slip speed and the rotor flux on d-axis.

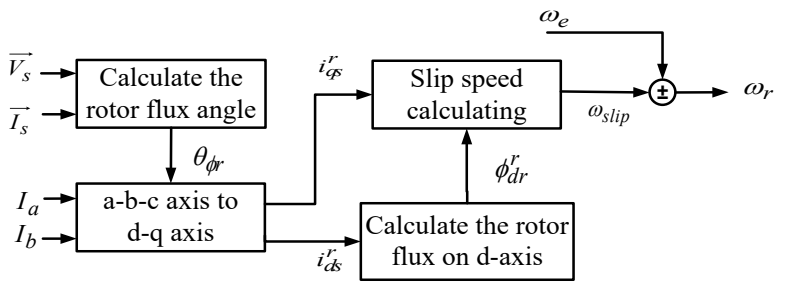

Fig 1. Block of slip speed estimator

$\overrightarrow{\phi_{r}}=\int \frac{L_{r}}{L_{m}}\left(\vec{V}_{s}-R_{S} \vec{I}_{s}-\left(1-\left(\frac{L m^{2}}{L_{S} L_{r}}\right)\right) L_{s} \frac{d}{d t} \overrightarrow{I_{s}}\right) d t$

\begin{tabular}{rlll} 
where & & & \\
\hline$\phi_{r}:$ & rotor flux & $V_{S}:$ & stator voltage \\
\hline$i_{S}:$ & stator current & $L_{S}:$ & stator inductance \\
\hline
\end{tabular}

\section{Scalar control}

In scalar control, the motor is driven by a suitable waveform. In Fig 2, the curve of speed versus voltage for a $200 \mathrm{krpm}$ motor is provided by the motor manufacturer. To drive motor in $30 \mathrm{krpm}$, the inverter should provide a three-phase sinusoidal wave with 57 volts and $500 \mathrm{~Hz}$. However, the real rotor speed is different from the driving speed due to the slip speed. Therefore, a PI controller is used in the proposed system to compensate the speed error caused by the slip speed. As shown in Fig 3, the input of controller is the speed error, and the output is the index of the VVVF table to set the inverter.

\section{Motor parameter measurement}

The IM's electric parameters are a key in slip speed estimation. Three parameter measuring tests are used in this paper. First, DC test is used to measure the stator resistor. Second, stall test could measure the sum of stator and rotor resistor, and the sum of stator and rotor leakage inductance. Then the rotor resistor can be obtained, and the stator and rotor leakage inductances, $L_{l s}$ and $L_{l r}$, are assumed equal. Third, no load test is adopted for the stator inductance, and then the mutual inductance could be derived. A virtual stall test is adopted, because a traditional stall test is not convenient due to extra stalling equivalent. Fig 4 is the wiring diagram of virtual stall test. 


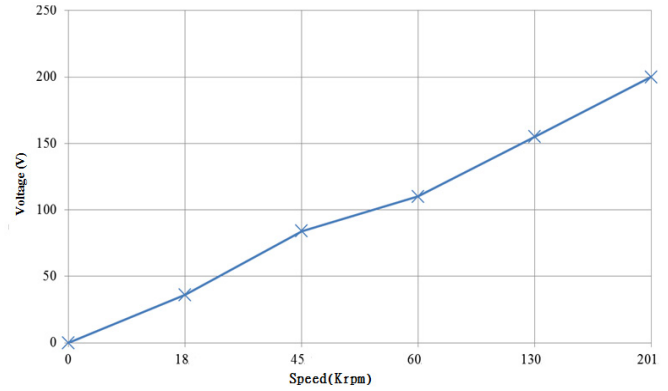

Fig 2. Speed-Voltage characteristic curve of $200 \mathrm{krpm}$ motor

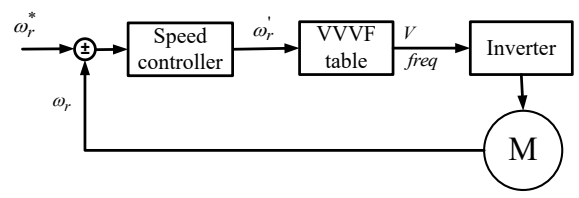

Fig 3. Block of scalar control

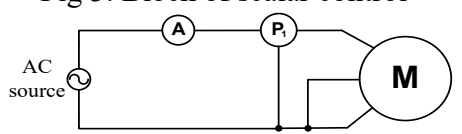

Fig 4. Wiring diagram of virtual stall test

Two ultra-high-speed motors are installed in experiments. The parameters of $200 \mathrm{krpm}$ and $300 \mathrm{krpm}$ motors are measured and shown in table 1.

Table 1. Parameters of $200 \mathrm{krpm}$ and $300 \mathrm{krpm}$ motor

\begin{tabular}{cccccc}
\hline Motor & $R_{S}$ & $L_{l s}$ & $R_{r}$ & $L_{l r}$ & $L_{m}$ \\
\hline $200 \mathrm{k}$ & $1 \Omega$ & $0.43 \mathrm{mH}$ & $2.84 \Omega$ & $0.43 \mathrm{mH}$ & $5.22 \mathrm{mH}$ \\
\hline $300 \mathrm{k}$ & $1.78 \Omega$ & $0.21 \mathrm{mH}$ & $4.33 \Omega$ & $0.21 \mathrm{mH}$ & $2.99 \mathrm{mH}$ \\
\hline
\end{tabular}

\section{System architecture and hardware implementation}

The control block diagram of system is shown in Fig 5 . Scalar control is used in the speed controller. A PI controller is adopted to create the speed command which is the index of the voltage-frequency curve. Here, a lookup table and the interpolation method are used to index the suitable voltage and frequency commands for the inverter. And, the feedback speed is calculated by speed of synchronization field and the slip speed computed from current and voltage.

Fig 6 presents the system architecture diagram. The feedback circuit is used to sense the motor current and DC BUS states for speed estimation. The microcontroller is applied in speed estimation and speed control, and generate driving signals for the inverter circuit. The inverter circuit converts $\mathrm{DC}$ voltage to $\mathrm{AC}$ driving waveform.

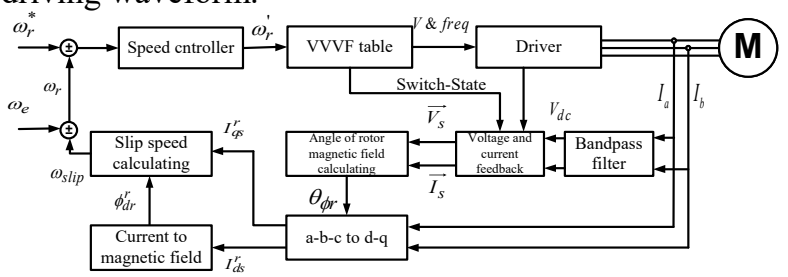

Fig 5. Control block diagram of system

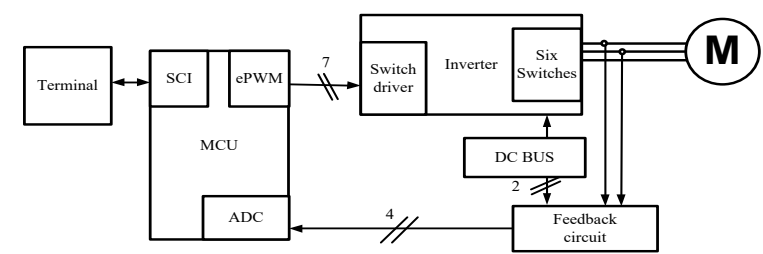

Fig 6. System architecture diagram

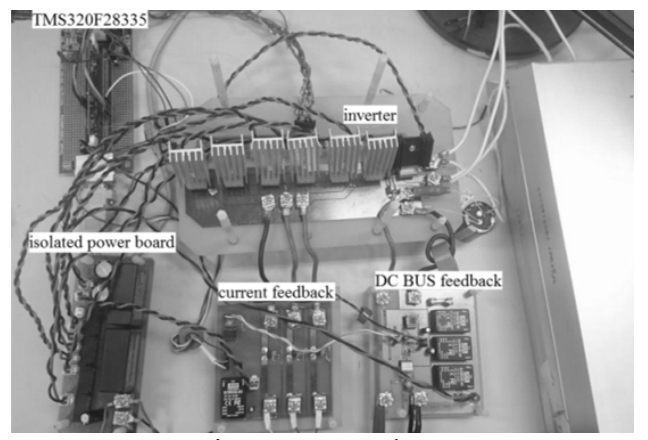

Fig 7. System photo

Fig 7 is the photo of the system proposed in this paper. The component at the upper left corner is TMS320F28335; at the lower left corner, an isolated power board; at the center, an inverter; at the lower middle, the current feedback circuit; and at the lower right corner, the DC BUS feedback circuit.

\section{Experimental results}

Two experimental results are shown in this paper: step and ramp acceleration. The experimental power supply rating is limited, so the step range and ramp acceleration of the speed are limited. Fig 8 shows the experimental results under $100 \mathrm{krpm}$ ramp command.

Table 2. Step and ramp acceleration of $200 \mathrm{krpm}$ motor

\begin{tabular}{|c|c|c|c|c|c|c|}
\hline & \multicolumn{3}{|c|}{ Step } & \multicolumn{3}{c|}{ Ramp acceleration } \\
\hline Speed command(rpm) & 40000 & 50000 & 60000 & 100000 & 120000 & 160000 \\
\hline Improved speed error (rpm) & 44 & 94 & 132 & 940 & 1600 & 4900 \\
\hline Percentage error(\%) & 0.11 & 0.18 & 0.22 & 0.94 & 1.33 & 3.06 \\
\hline Improved stability time(s) & 0.281 & 0.228 & $\mathrm{X}$ & 0.34 & 0.9 & 1.43 \\
\hline
\end{tabular}




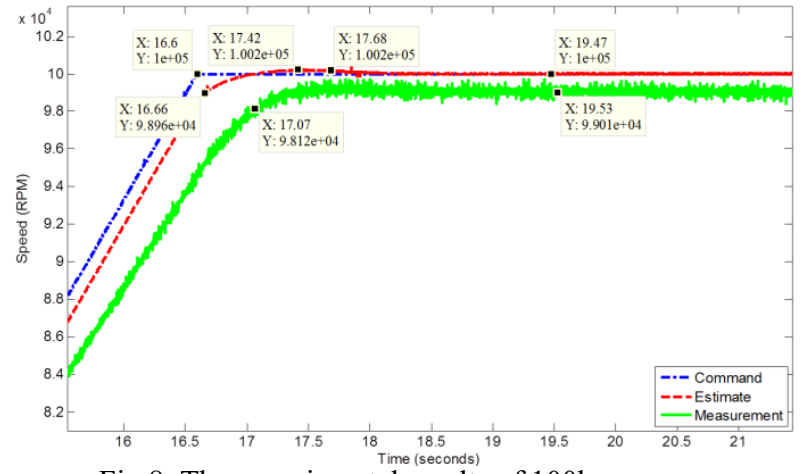

Fig 8. The experimental results of $100 \mathrm{krpm}$ ramp

The experimental results are shown in table 2, and the improved data of the proposed controller are compared with an open-loop driver. The speed error is reduced and proportional to speed command, and then stability time is improved in 0.2 to 1 seconds. Note that the experimental results of the $60 \mathrm{krpm}$ step for the proposed controller are not shown in this table because the required inrush current is over the capability of power supply.

In order to verify the proposed method is suitable for different motors, a motor rated $300 \mathrm{krpm}$ is adopted in the experiment. The speed errors of different commands in 200 and $300 \mathrm{krpm}$ motors are shown in Fig 9 and Fig 10 , respectively. Though the errors of the $300 \mathrm{krpm}$ motor are bigger than those of the $200 \mathrm{krpm}$ motor, but the trends in these two figures are the same. In addition, the error rate of the $200 \mathrm{krpm}$ motor is lower than $1.5 \%$, while that of the $300 \mathrm{krpm}$ motor is lower than 3.5\%.

\section{Conclusion}

As shown in experimental results, the motor with the proposed ultra-high-speed motor driver can achieve the stable state very fast. For practical purpose, the acceptable speed error ratio should be lower than $10 \%$. The proposed speed estimator can effectively estimate the motor speed and react the load fluctuation. Even though the speed error is proportional to speed command, the accomplished speed error rate is lower than $3.5 \%$, which is considered very small. Closed-loop controller actually improves the system responding time through the low-cost feedback circuit and reduces the sensitivity of motor parameters as compared with openloop system. The controller proposed in this paper is also suitable for different motors.

\section{Acknowledgment:}

This work is partially supported by the Ministry of Science and Technology, ROC, under contract No.
MOST 105-2221-E-224-024, 105-2218-E-150-004 and 104-2622-E-224-016 -CC3.

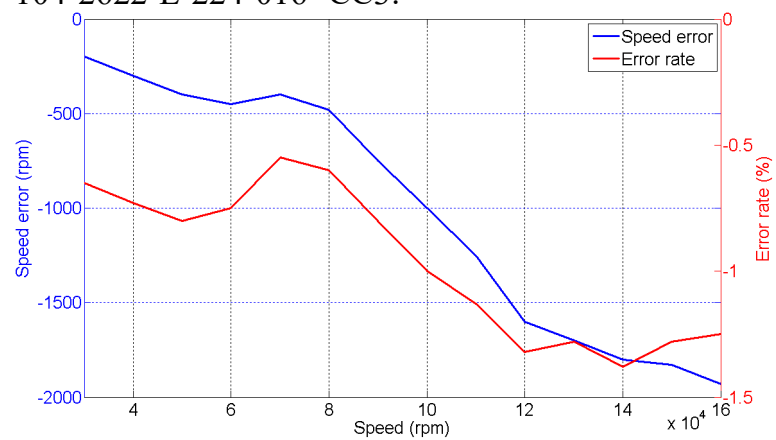

Fig 9. The error between estimated and measurement speed of

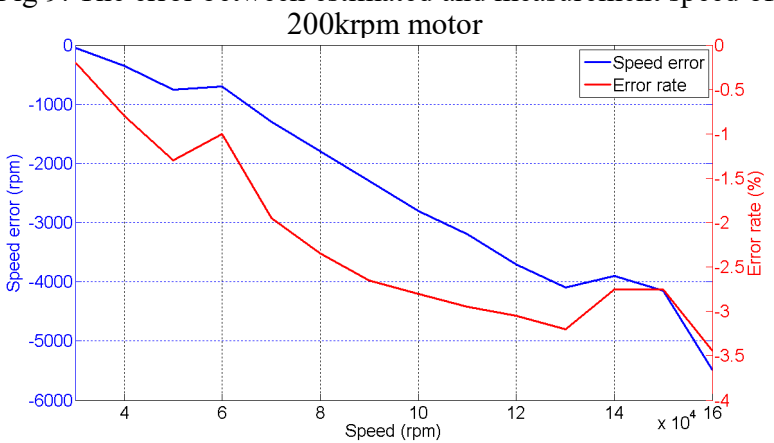

Fig 10. The error between estimated and measurement speed of $300 \mathrm{krpm}$ motor

\section{Reference}

1. C. H. Yang, "The automatically switching hybrid modulation driver for an ultra-high speed motor", National Digital Library of Theses and Dissertations in Taiwan, 2013.

2. B. F. Li, "The Research and Implementation of an Ultra-high Speed Soft Switch Inverter", National Digital Library of Theses and Dissertations in Taiwan, 2014

3. J. Li and Y. R. Zhong, "Efficiency Optimization of Induction Machines Based on Fuzzy Search Controller", IEEE International Conference on Machine Learning and Cybernetics, Vol. 4, pp. 2518 - 2522, Aug. 2005.

4. M. Tsuji, S. Chen, S. Hamasaki, X. D. Zhao and E. Yamada, "A Novel V/f Control of Induction Motors for Wide and Precise Speed Operation", SPEEDAM 2008 International Symposium on Power Electronics, Electrical Drives, Automation and Motion, pp. 1130 1135, Jun. 2008.

5. J. A. Santisteban and R. M. Stephan, "Vector Control Methods for Induction Machines: An Overview", IEEE Transactions on Education, Vol. 44, pp. 170 - 175, Aug. 2002

6. M. Bodson and J. Chiasson, "A Comparison of Sensorless Speed Estimation Methods for Induction Motor Control", American Control Conference on Proceedings, Vol. 4, pp. 3046 - 3081, May 2002 